\title{
Inhaltsverzeichnis.
}

\author{
Kapitel I. \\ Henge und Funktion. (Aualyse der mathematisehen Begriffoblidung.) \\ Logischer Teil. 8 8eito \\ § 1. Eigenschaft, Relation, Existenz . . . . . . . . . . . . 1 \\ \& 2. Die Prinzipien der Urteilskombination . . . . . . . . . 4 \\ § 3. Logisches SchlieBen. Axiomatische Methode . . . . . . . 8
}

Mathematischer Teil.

§. Mengen . . . . . . . . . . . . . . . . . . . . . 13

\$ 5. Die natürlichen Zablen. Richardsche Antinomie . . . . . . 17

$\$ 6$. Iteration des mathematischen Prozesses. Der circulus vitiosus der Analysis . . . . . . . . . . . . . . . . . . . 19

\& 7. Substitutions- und Iterationsprinzip . . . . . . . . . . . 26

$\S 8$. Endgültige Formulierung der Grundlagen. - Einführung idealer Elemente . . . . . . . . . . . . . . . . . . . . 29 SchluBbemerkungen . . . . . . . . . . . . . . . . 34

\section{Kapitel II.}

Zahlbegrif und Kontinuum. (Grundlagen der Infinitesimalrechuung.)

$\$ 1$. Natürliche Zahlen und Anzahlen . . . . . . . . . . . . 39

$\$ 2$. Brüche und rationale Zahlen . . . . . . . . . . . . . 14

§. Reelle Zahlen. . . . . . . . . . . . . . . . . . . 51

4. Zahlfolgen. Konvergenzprinzip . . . . . . . . . . . . 57

5. Stetige Funktionen . . . . . . . . . . . . . . . . . 61

$\$ 6$. Anschauliches und mathematisches Kontinuum. . . . . . 65

\$ 7. GröBen. MaBzablen . . . . . . . . . . . . . . . . . 74

§. Kurven und Flächen . . . . . . . . . . . . . . . . 77 
